\title{
SKRINING FITOKIMIA DAN PENETAPAN KANDUNGAN FLAVONOID TOTAL EKSTRAK METANOLIK HERBA BOROCO (Celosia argentea L.)
}

\author{
Abd.Malik, Ferawati Edward, Risda Waris, \\ Laboratorium Farmakognosi Fitokimia \\ Universitas Muslim Indonesia \\ abd.malik@umi.ac.id
}

\begin{abstract}
Phytochemical Screening and Determination of Total Flavonoids Content of Methanolic Extracts of Boroco Herbs (Celocia argentea L). Boroco plant is often used as a traditional medicine for anti inflammatory, diuretic, hypertension, dysentery. Chemical constituents in boroco herbs (Celocia argentea L.) are alkaloids and flavanoids, glycosides, tannin and saponin (2003). Each sample extraction using $96 \%$ methanol of maceration method. Then performed to determine the class of phytochemical screening of active compounds are contained in the sample. Determination of total flavanoids done by chang et al method (2002) of Boroco herbs. Result of the study showed the total flavanoids content of methanolic extract of boroco herbs calculated as a rutin for $2.57 \%$.
\end{abstract}

Keywords: Boroco (Celosia argentea L.), Rutin, Flavonoid Total

I. PENDAHULUAN

Latar Belakang

Boroco bernama latin Celosia argentea L., yang termasuk kedalam family tumbuhan Amaranthaceae. Tanaman ini dikenal dengan nama-nama daerah seperti bayam ekor belanda, bayam kucing (Bangun, 2012).

Tanaman Boroco ini adalah tumbuhan yang tumbuh tegak, tingginya sekitar 30-100 sentimeter, sering tumbuh liar di sisi jalan, pinggir selokan, tanah lapang terlantar. Batangnya bulat dengan alur kasar memanjang, bercabang banyak, warna ijau atau merah. Daunnya berwarna hijau atau merah, berbentuk bulat telur memanjang, ujung lancip, tepinya bergerigi halus hampir rata.Bunganya bulir panjang 3-10 sentimeter, warna merah muda atau ungu, bijinya hitam cerah, bunga tumbuh di ujung-ujung cabang (Bangun, 2012).

Boroco biasa ditemukan liar di daerah berpasir yang basah, seperti di tepi selokan atau di tepi sungai, tegalan, kebun dan semak. Kadang juga dibudidayakan sebagai tanaman hias atau sayuran. Asalnya mungkin dari Amerika, tersebar ke cina selatan, Sri lanka, India, Afrika. Di Indonesia dapat ditemukan pada ketinggian 1-1.700 $\mathrm{m}$ di atas permukaan laut (Dalimartha, 2003).

Perbanyakan tanaman boroco dapat dilakukan dengan biji atau setek. Seluruh bagian tanaman boroco, baik segar maupun kering dapat digunakan untuk mengobati beberapa penyakit (Permadi, 2006).

Herba Boroco mengandung flavonoid dan polifenol. (Dalimartha,2003). Senyawa flavonoid adalah senyawa polifenol dengan inti terdiri dari 15 atom karbon, tersusun atas dua cincin gugus benzene yang dihubungkan menjadi satu oleh rantai linier yang terdiri dari 3 atom karbon. Flavonoid umumnya terdapat pada tumbuhan terikat dengan gula sebagai glikosida (Sovia, 2006).

\section{METODE PENELITIAN}

\section{A. Pengolahan Sampel}

Bahan penelitian berupa herba, kemudian dibersihkan dengan air mengalir hingga bersih, lalu dikeringkan pada tempat yang tidak terkena sinar matahari langsung, setelah itu dirajang dan diserbukkan.

\section{B. Metode Esktraksi}

Serbuk simplisia ditimbang 300 gram kemudian dimasukkan dalam wadah maserasi. Cairan pengekstraksi metanol sebanyak $1 \mathrm{~L}$ dimasukkan kedalam wadah maserasi, biarkan beberapa jam kemudian tambahkan $1 \mathrm{~L}$ metanol hingga seluruh serbuk sampel terendam, lalu ditutup rapat. Wadah maserasi disimpan pada tempat yang terlindungi dari cahaya matahari langsung selama 5 hari sambil dilakukan pengadukan sesering mungkin. Campuran kemudian disaring dan ampasnya 
direndam lagi dengan cairan penyari yang baru. Proses penyarian selanjutnya dilakukan sebanyak 4 kali dengan metanol setiap kali sebanyak 2 L. Ekstrak cair dikumpulkan kemudian dipekatkan dengan menggunakan alat Rotavapor hingga diperoleh ekstrak metanol kental.

\section{Skrining Fitokimia \\ a. Uji Alkaloid}

Ditimbang $500 \mathrm{mg}$ serbuk simplisia, Ditambahkan $1 \mathrm{~mL}$ asam klorida $2 \mathrm{~N}$ dan $9 \mathrm{~mL}$ aquadest, panaskan di atas tangas air selama 2 menit, dinginkan dan saring, pindahkan 3 tetes filtrat pada kaca arloji, tambahkan 2 tetes larutan Bouchardat (Jika terdapat endapan berwarna cokelat sampai hitam, maka serbuk mengandung alkaloid), tambahkan 2 tetes larutan Mayer (Jika terbentuk endapan menggumpal berwarna putih atau kuning yang larut dalam metanol $\mathrm{P}$, maka sebuk mengandung alkaloid).

\section{b. Uji Flavonoid}

- Larutan Percobaan

Sari $0,5 \mathrm{~g}$ serbuk yang diperiksa atau sisa kering $10 \mathrm{~mL}$ sediaan berbentuk cairan, dengan $10 \mathrm{~mL}$ metanol $\mathrm{P}$, menggunakan alat pendingin balik selama 10 menit. Saring panas melalui kertas saring kecil berlipat, encerkan filtrat dengan $10 \mathrm{~mL}$ air. Setelah dingin tambahkan $5 \mathrm{~mL}$ eter minyak tanah $\mathrm{P}$, kocok hati-hati diamkan. Ambil lapisan metanol, uapkan pada suhu $40^{\circ}$ dibawah tekanan. Sisa dilarutkan dalam $5 \mathrm{~mL}$ etil asetat $\mathrm{P}$, saring.

- Cara Kerja

1. Uapkan hingga kering $1 \mathrm{~mL}$ larutan percobaan, sisa dilarutkan dalam $1 \mathrm{~mL}$ sampai $2 \mathrm{~mL}$ etanol (95\%) $\mathrm{P}$, tambahkan $0,5 \mathrm{~g}$ serbuk seng $\mathrm{P}$ dan 2 $\mathrm{mL}$ asam klorida $2 \mathrm{~N}$, diamkan selama 1 menit. Tambahkan 10 tetes asam klorida pekat $\mathrm{P}$, jika dalam waktu 2 menit sampai 5 menit terjadi warna merah intensif, menunjukkan adanya flavonoid (glikosida-3-flavonol).

2. Uapkan hingga kering $1 \mathrm{~mL}$ larutan percobaan, sisa dilarutkan dalam $1 \mathrm{~mL}$ etanol (95\%) P, tambahkan 0,1 g serbuk magnesium $\mathrm{P}$ dan 10 tetes asam klorida $\mathrm{P}$, jika terjadi warna merah jingga sampai merah ungu, menunjukkan adanya flavonoid. Jika terjadi warna kuning jingga, menunjukkan adanya flavon, kalkon dan auron.

3. Uapkan hingga kering $1 \mathrm{~mL}$ larutan percobaan, basahkan sisa dengan aseton $\mathrm{P}$, tambahkan sedikit serbuk halus asam borat $\mathrm{P}$ dan serbuk halus oksalat $\mathrm{P}$, panaskan hati-hati diatas tangas air dan hindari pemanasan yang berlebihan. Campur sisa yang diperoleh dengan $10 \mathrm{~mL}$ eter P. Amati dengan sinar UV $366 \mathrm{~nm}$, larutan berfluorosensi kuning intensif, menunjukkan adanya flavonoid.

\section{c. Uji Glikosida}

- Larutan Percobaan

Sari filtrat 3 kali, tiap kali dengan 20 $\mathrm{mL}$ campuran 3 bagian volume kloroform $\mathrm{P}$ dan 2 bagian volume isopropanol P. Pada kumpulan sari tambahkan natrium sulfat anhidrat $\mathrm{P}$, saring, dan uapkan pada suhu tidak lebih dari $50^{\circ}$. Larutan sisa dengan $2 \mathrm{~mL}$ metanol P.

- Cara Percobaan

1. Uapkan $0,1 \mathrm{~mL}$ larutan percobaan di atas tangas air, larutkan sisa dalam 5 $\mathrm{mL}$ asam asetat anhidrat $\mathrm{P}$. Tambahkan 10 tetes asam sulfat $\mathrm{P}$, terjadi warna biru atau hijau menunjukkan adanya glikosida (reaksi Liebermann Burchard).

2. Masukkan 0,1 mL larutan Percobaan dalam tabung reaksi, uapkan di atas tangas air. Pada sisa tambahkan $2 \mathrm{~mL}$ air dan 2 tetes Molish LP. Tambahkan hati-hati $2 \mathrm{~mL}$ asam sulfat $\mathrm{P}$, terbentuk cincin berwarna ungu pada batas cairan, menunjukkan adanya ikatan gula (reaksi Molish).

\section{d. Uji Saponin}

Masukkan 0,5 g serbuk kedalam tabung reaksi, tambahkan $10 \mathrm{~mL}$ air panas, dinginkan dan kocok kuat-kuat selama 10 detik jika zat yang diperiksa berupa sediaan cair, encerkan $1 \mathrm{~mL}$ sediaan, tambahkan $10 \mathrm{~mL}$ air dan kocok kuat-kuat selama 10 menit, terbentuk buih yang mantap selama tidak kurang dari 10 menit, setinggi $1 \mathrm{~cm}$ sampai 10 $\mathrm{cm}$. Pada penambahan 1 tetes asam klorida $2 \mathrm{~N}$, buih tidak hilang.

\section{e. Uji Tanin (Fransworth, 1966)}

Sejumlah $200 \mathrm{mg}$ ekstrak kental dilarutkan dalam $5 \mathrm{~mL}$ air suling panas dan diaduk. Setelah dingin disentrifugasi dan 
bagian cairan didekantisir dan diberi larutan $\mathrm{NaCl} 10 \%$ kemudian disaring. Filtrat sebanyak masing-masing $1 \mathrm{~mL}$ dikerjakan sebagai berikut :

a. Tambahkan $3 \mathrm{ml}$ larutan gelatin $10 \%$ dan diperhatikan endapannya.

b. Tambahkan 2 tetes larutan $\mathrm{FeCl}_{3}$, dan diperhatikan terjadinya perubahan warna menjadi hijau violet.

c. Ditambahkan $3 \mathrm{~mL}$ larutan $\mathrm{NaCl}$-gelatin (gelatin 1\% dalam larutan $\mathrm{NaCl} 10 \%$ ) dan diperhatikan adanya endapan.

\section{Penentuan Kandungan Flavonoid Total} (Chang et al, 2002).

Ekstrak sebanyak $10 \mathrm{mg}$ dilarutkan dalam $10 \mathrm{~mL}$ metanol, diambil $1 \mathrm{~mL}$ kemudian ditambahkan $3 \mathrm{~mL}$ metanol, 0,2 $\mathrm{mL} \mathrm{AlCl} 3$ $10 \%, 0,2 \mathrm{~mL}$ kalium asetat, 5,6 mL aqubedistilata, simpan 30 menit pada tempat gelap dengan suasana suhu kamar, absorbansinya di ukur pada spektrofotometri $\mathrm{UV}-\mathrm{V}$ is dengan panjang gelombang $415 \mathrm{~nm}$. Kadar flavonoid total dinyatakan dalam gram rutin equivalen $(\mathrm{RE})$.

\section{HASIL DAN PEMBAHASAN}

\section{A. Hasil Penelitian}

Tabel 1. Hasil Skrining Fitokimia dari Herba Buroco

\begin{tabular}{|c|c|}
\hline Skrining Fitokimia & Sampel \\
\hline Uji alkaloid & + \\
\hline Uji flavonoid & + \\
\hline Uji glikosida & + \\
\hline Uji saponin & + \\
\hline Uji tannin & + \\
\hline
\end{tabular}

Tabel 2. Hasil pengukuran absorbansi larutan standar rutin

\begin{tabular}{|c|c|}
\hline Konsentrasi (ppm) & Absorbansi \\
\hline 2 & 1,023 \\
\hline 4 & 1,338 \\
\hline 8 & 1,735 \\
\hline 10 & 1,89 \\
\hline
\end{tabular}

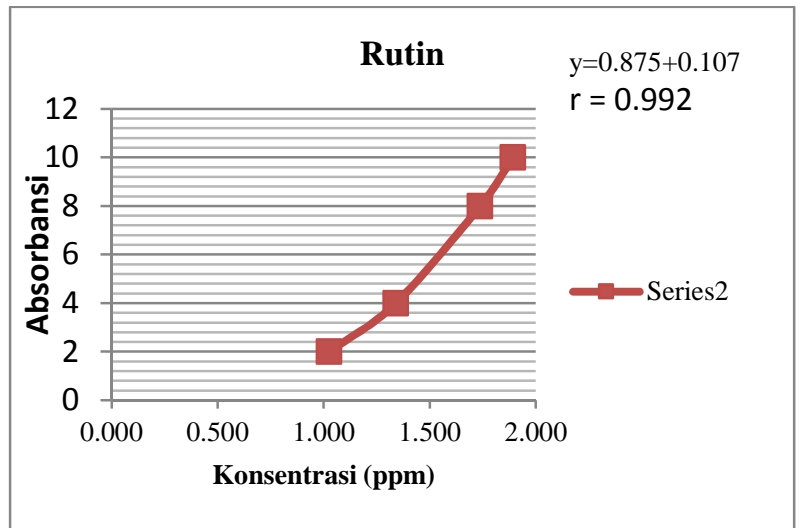

Gambar 2. Kurva kalibrasi rutin pada panjang gelombang $415 \mathrm{~nm}$

Tabel 3. Hasil pengukuran kadar flavonoid total

\begin{tabular}{|c|c|c|c|}
\hline Sampel & Absorbansi & Konsentrasi & $\begin{array}{c}\text { Flavonoid } \\
\text { Total }\end{array}$ \\
\hline $\begin{array}{c}\text { Ekstrak } \\
\text { herba } \\
\text { boroco }\end{array}$ & 1,895 & 25,71 & 2,57 \\
\hline
\end{tabular}

\section{B. Pembahasan}

Tanaman herba Boroco (Celosia argentea $\mathrm{L}$ ) dikumpulkan kemudian dilakukan proses pencucian, sortir basah dan kering untuk mendapatkan simplisia. Tanaman herba Boroco (Celosia argentea L) dikeringkan dengan cara dijemur ditempat yang tidak terkena sinar matahari langsung. Setelah kering sampel diserbukkan. Kemudian dilakukan ekstraksi dengan metode maserasi. Metode maserasi dipilih dalam penelitian ini karena merupakan metode yang mudah dilakukan dan menggunakan alat-alat sederhana, yaitu cukup dengan merendam sampel dalam pelarut (Voigt, 1995).

Pelarut yang digunakan dalam penelitian ini adalah metanol. Digunakan metanol karena pelarut ini dapat melarutkan hampir semua senyawa organik yang ada pada sampel, mudah menguap sehingga mudah dibebaskan dari ekstrak (Andayani, et al. 2008). Rendaman pada saat maserasi disimpan ditempat yang terlindungi dari cahaya, hal ini dilakukan untuk mencegah reaksi yang dikatalisis cahaya atau mencegah terjadinya perubahan warna (Voigt, 1995).

Setelah didapatkan ekstrak, dilakukan skrining fitokimia untuk menentukan golongan senyawa aktif dari tanaman ini. Skrining fitokimia merupakan cara sederhana untuk 
melakukan analisis kualitatif kandungan senyawa yang terdapat dalam tumbuhan. Pada penelitian ini skrining yang dilakukan adalah uji alkaloid, uji flavanoid, uji saponin, uji tannin, dan uji glikosida. Karena uji-uji tersebut sudah mewakili beberapa golongan senyawa yang terdapat dalam tanaman.

Hasil skrining fitokimia dari herba boroco (Celosia argentea L) pada tabel 1 menunjukkan positif (+) untuk uji alkaloid, uji flavonoid, uji tannin, uji saponin dan uji glikosida. Hasil tersebut berbeda dengan literatur yang mendapatkan hasil negatif (-) uji glikosida.

Analisa kandungan flavonoid total pada penelitian ini dilakukan dengan menggunakan larutan standar rutin dengan konsentrasi $(\mu \mathrm{g} / \mathrm{mL}) 2,4,8$, dan 10 pada tabel 2 berturut-turut menghasilkan absorbansi $1,023,1,338,1,734,1,89$ dengan warna yang dihasilkan adalah warna kuning. Senyawa rutin adalah zat padat, berwarna kuning dan larut dalam air, tetapi rutin ini lebih banyak larut dalam air dibandingkan aglikon kuersetin (Fitria, 2007).. Semakin tinggi konsentrasi yang digunakan, maka semakin pekat warna kuning yang akan dihasilkan. Digunakan larutan standar rutin karena kebanyakan flavonoid yang paling sering ditemukan dalam tanaman dalam bentuk glikosida seperti kuarsetin 3-rutinosida (Harbone, 1998).

Berdasarkan Gambar 1 dapat dilihat bahwa kurva kalibrasi dengan persamaan regresi untuk absorbansi rutin sebesar $\mathrm{y}=$ $0.875+0.107$. Larutan standar senyawa flavonoid diperoleh hubungan yang linear antara absorbansi dengan konsentrasi pada pengukuran absorbansi yang ditunjukkan dengan nilai koefisien korelasi sebesar 0.992 Nilai (r).

Absorbansi ekstrak metanol herba boroco sebanyak 1,895. Dari nilai absorbansi tersebut dapat diketahui konsentrasi flavonoid dari ekstrak metanol herba boroco dengan menggunakan persamaan regresi menghasilkan konsentrasi (mg/L) sebesar 25,71. Untuk pengukuran kadar flavonoid total ekstrak herba boroco diawali dengan pembuatan larutan standar rutin, ditimbang $2,5 \mathrm{mg}$ rutin dan dilarutkan dalam $10 \mathrm{~mL}$ methanol pa menghasilkan 1000 ppm. Larutan standar rutin dibuat menjadi beberapa konsentrasi (ppm) yaitu 2, 4, 8 dan 10. Ini dimaksudkan untuk mengurangi ketidakpastian analisa sehingga ketelitian akan meningkat (Wiryawan, 2008).
Masing-masing konsentrasi rutin dipipet $1 \mathrm{~mL}$ dan di reaksikan dengan $3 \mathrm{ml}$ metanol yang berfungsi sebagai peningkat kelarutan, ditambah $0,2 \mathrm{ml} \quad \mathrm{AlCl}_{3} \quad 10 \%$ yang berfungsi untuk memberikan efek batokromik yaitu menggeser ke panjang gelombang yang lebih tinggi dan terjadi juga peningkatan intensitas larutan standar rutin menghasilkan warna yang lebih kuning sehingga reaksi warna yang terbentuk dapat diamati dengan mata telanjang dan dapat diukur pada spektrofotometri UV-Vis. Kemudian ditambahkan 0,2 $\mathrm{ml}$ kalium asetat yang berfungsi sebagai penstabil agar efek batokromik yang terjadi dapat dipertahankan. Lalu ditambahkan 5,6 ml aquabidestilata, menghasilkan warna kuning. Didiamkan pada suhu kamar dalam keadaan gelap selama 30 menit agar reaksi antara larutan standar rutin dengan pereaksi-pereaksi dapat berlangsung sempurna.

Pada pengukuran absorbansi sampel, ditimbang $10 \mathrm{mg}$ ekstrak dan dilarutkan dengan $10 \mathrm{ml}$ methanol pa lalu dipipet $1 \mathrm{ml}$ dari larutan sampel dan ditambahkan $3 \mathrm{ml}$ methanol, 0,2 ml $\mathrm{AlCl} 310 \%, 0,2 \mathrm{ml}$ kalium asetat dan aquabidestillata. Kemudian diukur absorbansinya dengan spektrofotometri UVVis pada panjang gelombang $415 \mathrm{~nm}$.

Hasil tersebut dimasukan dalam rumus, penentuan kadar flavonoid total berdasarkan tesis (Malik, 2011) yaitu:

Konsentrasi x Vol.Ekstrak x 100

flavonoid total $=$

Berat ekstrak

Hasil yang diperoleh pada tabel 3 dari penentuan kadar flavonoid total dalam estrak metanol herba boroco yaitu $2,57 \%$.

\section{KESIMPULAN}

Dari hasil penelitian yang telah dilakukan, dapat diambil kesimpulan bahwa kadar flavonoid total pada ekstrak metanol herba boroco (Celosia argentea $\mathrm{L}$ ) yaitu 2,57 $\%$.

\section{DAFTAR PUSTAKA}

1. Ahmad, S.A., 1980. Kimia Organik Bahan Alam. Penerbit Kurnia : Jakarta.

2. Andayani, Yovita dan Maimunah. 2008. Penentuan Aktivitas Antioksidan, Kadar Fenolat Total dan Likopen pada Buah Tomat (Solanum lycopersicum L). Jurnal 
Sains dan Teknologi Farmasi. UNAND: Padang.

3. Bangun, Abednego. 2012. Ensiklopedia Tanaman Obat Indonesia. Indonesia Publishing House. 2012.

4. Chang, C. Yang, M. Wen, H. and Chern J. 2002. Estimation of total flavonoid content in Propolis by two complementary colorimetric methods.J . FoodDrug A.

5. Direktorat Jenderal Pengawasan Obat dan Makanan, 1979. Farmakope Indonesia Edisi III. Departemen Kesehatan RI : Jakarta.

6. Direktorat Jendral Pengawasan Obat dan Makanan.1995 Farmakope Indonesia Edisi IV.Departemen Kesehatan RI, Jakarta.

7. Direktorat JendraI.Pengawasan Obat dan Makanan. 2000. Parameter Standar Umum Ekstrak Tumbuhan Obat. Departemen Kesehatan RI, Jakarta.

8. Dalimartha,S. 2003. Altas Tumbuhan Obat Indonesia Volume 3. Niaga Swadaya. Jakarta.

9. Fitria. 2007. Isolasi dan Identifikasi Senyawa Flavonoid Dalam Daun Paliasa. Universitas Hasanuddin : Makassar.

10. Harborne, J.B. 1987. Metode Fitokimia : Penuntun cara modern menganalisa tumbuhan. Terbitan Kedua. Terjemahan Kosasih Padmawinata dan Iwang Soediro. ITB : Bandung.

11. Hendayana S. 1997. Kimia analisis instrument. ikip semarang press.

12. Markham, K.R. 1998. Cara Mengindentifikasi Flavonoid, terjemahan K. Radmawinata, Penerbit ITB : Bandung.

13. Martawijaya,M. 1989. Atlas Кауи Indonesia. Jilid 3. Departemen Kehutanan. Badan Penelitian Dan Pengembangan Kehutanan : Bogor.

14. Miller AL. 1996. Antioxidant flavonoids: structure, function, and clinical usage. Alt Med Rev 1
15. Mujahid.2011.TESIS pemilihan metode analisis flavonoid secara spektroskopi UV-Vis serta penerapannya pada seledri (apium graviolens L) murbei (morus alba L), patikan kebo (euphorbia hirta L) dan jeruk nipis (citrus aurantifolia).Program pascasarjana program studi ilmu farmasi.fakultas farmasi.UGM. Yogyakarta.

16. Nugroho, A.E; Malik, A and Promono, S.2013. Total Phenolic And Flavonoid Contents, And In Vitro Antihypertension Activity Of Purified Extract Of Indonesia Cashew Leaves. International food research journal. 20(1):299-305.

17. Sastrohamidjojo, Hardjono. 1985. Kromatografi. Yogyakarta : Liberty yogyakarta.

18. Sovia,L. 2006. Senyawa Flavonoida, Fenilpropanoida, dan Alkaloida[Karya Ilmiah]. Fakultas Matematika dan Ilmu Pengetahuan Alam. Universitas Sumatera Utara : Medan.

19. Underwood AL.1996. analisa kimia kuantitatif,ed IV.erlangga.jakarta

20. Wildah,Dj. 2001. Isolasi dan Identifikasi Flavonoid Pada Daun Kemuning [Skripsi]. Jurusan Farmasi Fakultas MIPA. Universitas Hasanuddin : Makassar.

21. Wiryawan A, dkk. 2008. Kimia Analitik. Departemen Pendidikan Nasional : Jakarta. 